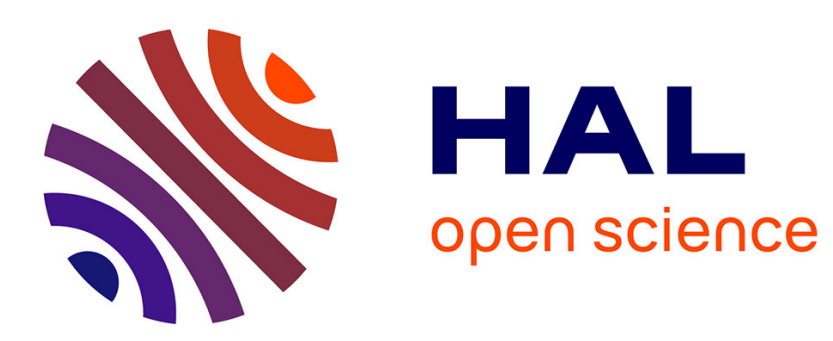

\title{
ON THE EQUATION OF STATE OF SOLID AND LIQUID ALKALI METALS
}

S. Stishov, I. Makarenko, A. Nikolaenko

\section{To cite this version:}

S. Stishov, I. Makarenko, A. Nikolaenko. ON THE EQUATION OF STATE OF SOLID AND LIQUID ALKALI METALS. Journal de Physique Colloques, 1980, 41 (C8), pp.C8-573-C8-576. 10.1051/jphyscol:19808144 . jpa-00220243

\section{HAL Id: jpa-00220243 https://hal.science/jpa-00220243}

Submitted on 1 Jan 1980

HAL is a multi-disciplinary open access archive for the deposit and dissemination of scientific research documents, whether they are published or not. The documents may come from teaching and research institutions in France or abroad, or from public or private research centers.
L'archive ouverte pluridisciplinaire HAL, est destinée au dépôt et à la diffusion de documents scientifiques de niveau recherche, publiés ou non, émanant des établissements d'enseignement et de recherche français ou étrangers, des laboratoires publics ou privés. 
ON THE EQUATION OF STATE OF SOLID AND LIQUID ALKALI METALS

S.M. Stishov, I.N. Makarenko and A.M. Nikolaenko

Institute of crystaZlogrophy, Academy of Sciences of USSR, Moscow, U.S.S.R.

Abstract.- It is shown that high temperature experimental $\mathrm{P}-\mathrm{V}-\mathrm{T}$ data for alkali metals contain information that permits calculation of the $O \mathrm{~K}$ compression isotherm for the solid, and P-V relations for the liquid which could be interpreted as $0 \mathrm{~K}$ compression isotherms for a supercooled liquid. It appears that the $0 \mathrm{~K}$ isotherms for liquids and solids coincide within experimental and calculational errors except, possibly, for lithium. Some consequences are discussed.

For a number of years we have studied the solid and liquid equations of state (EOS) for the alkali metals at pressures to $2 \mathrm{GPa}$ and temperatures between 293 and $523 K[1,2]$. Analysis of the data showed that polynomials of the form

$$
p=\alpha T+b T^{2}+c T / V+\sum_{i} \alpha_{i} V^{-i}
$$

where $P, V$ and $T$ are the pressure, specific volume, and temperature, respeotively, and $a, b, c$ and the $\alpha_{i}$ are constants found from the data, could be used with great success for the solid at temperatures of the order of $\theta_{D}$ and higher.

The mean deviation of Eq .1 from the data was less than the estimated experimental error of $1 \mathrm{MPa}$. The empirically determined form of $\mathrm{Eq} .1$ agrees with the idea that the free energy of normal solids can be represented as the sum of the temperature - Independent potentlal energy, the zero point energy, and the thermal energy. The calculations results in small values for 6 and $c$ in Eq .1 and, consequently, the derivative $(\alpha P / d T)_{V}$ is a weak function of $P$ and $T$, in agreement with theory [3]. Thus the form of Eq .1 seems to be quite reasonable.

However, it is not clear that $\mathrm{Eq} .7$, with coefficients found from high temperature data, can be used to predict $T=O K$ properties. The answer to this question is important because it is much more convenient to do experiments at moderate than at liquid helium temperatures.

Firgt, we examine what kind of information about the ground state could be contained in the high temperature data.

The crystal energy in the Debye approximation is

$$
U=U_{s t}+(9 / 8) R \theta_{D} \div 3 R T f\left(\theta_{D} / T\right),(2)
$$
where the terms are, respectively, the static, zero point, and thermal energies. 
At $T \gg \theta_{D}$ the term $3 R T_{f}\left(\theta_{D} / T\right)$ can be written as $3 R T-(9 / 8) R \theta_{D}$ and, using the first term of the anharmonic correction, $E q$.? is

$$
U=U_{s t}+3 R T+A T^{2}
$$

It follows from $\mathrm{Eq} .3$ that :

$$
P-P_{s}=P_{s t}-(d A / d V)_{T} T^{2}
$$

where $P_{S}=T(d S / d V)_{T}$ is the entropy contribution to the pressure from

$$
d F / d V=-P=d U / d V-T d S / d V \text {. }
$$

Thus we can extract information about the static lattice pressure by taking into account contributions of the entropy and anharmonic terms. However, in the high temperature approximation ( $\mathrm{Eq} .3)$, information about the pressure due to zero point energy is lọst.

In the case of an EOS of the form of $\mathrm{Eq} .1$, it is easy to see that

$$
P-P_{s}=\sum_{i} \alpha_{i} V^{-i}-b T^{2}
$$

and, therefore,

$$
P_{s t}=\sum_{i} \alpha_{i} V^{-i}
$$

Verification of $\mathrm{Eq} .6$ can be done readily using compression data for the alkali metals at $4.2 \mathrm{~K}[4-8]$. We note that we use the Debye approximation to take into account the pressure due to the zero point motion.

Comparison of the results of our calculations and experimental data (see Fig.1) shows very good agreement. We conclude that extracting information about the

$T=O K$ state is possible using only high temperature data.

Now we turn to the liquid alkali metals.

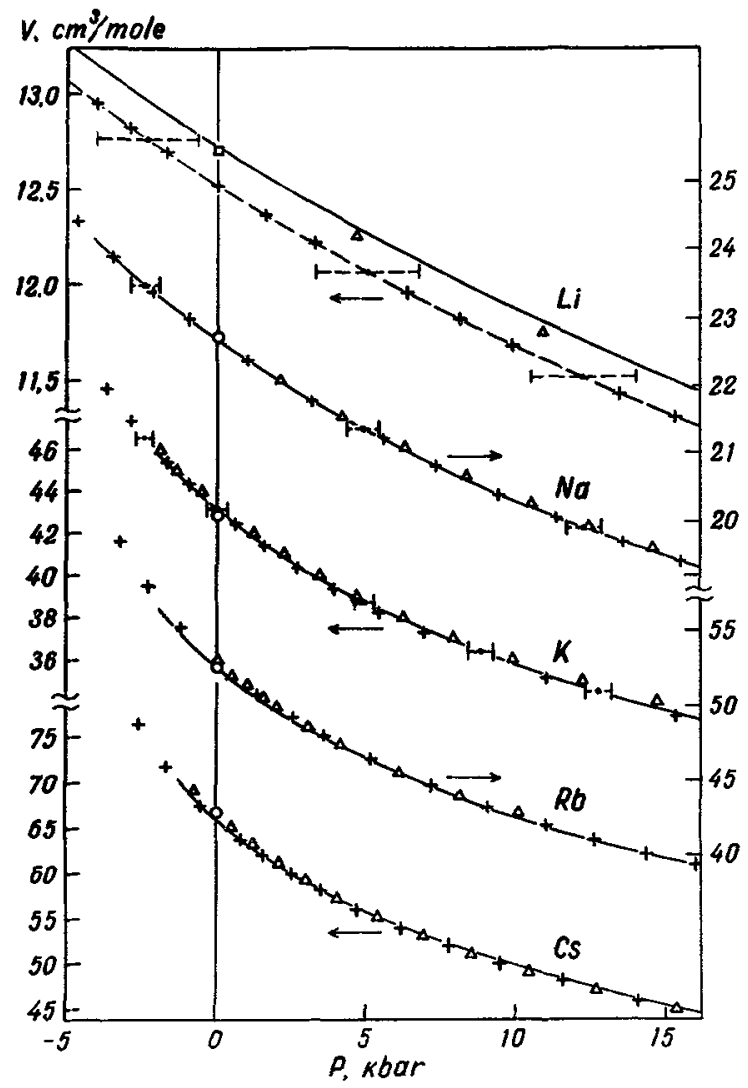

Fig.1.- Equation of atate for alkali metals at zero temperature. Our calculations: - crystal, + - "liquid". Uncertainties, if not presented on the graph, one not more than $10 \mathrm{MPa}$.

$$
\Delta-[4-8] ; \square-[12] ; 0-[13] \text {. }
$$

It appeared that equation (1) describes adequately $\mathrm{P}-\mathrm{V}-\mathrm{T}$ data for liquid alkall metals. It is not surprising because thermodynamic properties of solid and liquid alkali metals are quite gimilar. For Instance, the compressibilities of liquid and solid are very close and both have a small temperature dependence $[1,2]$. It is worth emphasizing here that in the case of liquid noble gases the values of compressibility, and especially their temperature dependences, are much higher than those for solids $[9,10]$. 
Next, we assume that the thermodynamics of liquid alkali metals can be developed in the same way as for the solids, i.e., in terms of the ground state and thermal excitations. Then, $P_{s t}=\sum_{i} \alpha_{i} V^{-i}$, extracted from the high temperature equation of state, can be used to find the pressure of the "liquid" ground state, minus the zero point contribution. Here, $P_{s t}$ is the pressure owing to some static configuration af atoms. Using the Debye approximation to estimate roughly the zero point energy of the "liquid" we can compare the zero point "liquid" isotherm with the corresponding one for the crystal.

As can be seen from the Fig. 1 the zero point "liquid" isotherms are the same as for the solid alkali metals within the experimental and calculational uncertainties. An exception may be lithium, where the situation is not yet clear.

This rather unexpected result leads to the conclusion that the energies of the "liquid" and crystalline alkali metals along the $O \mathrm{~K}$ isotherm differ almost by a constant.
If, for lithium, the observed differences are real, the "liquid" zero point isotherm occurs at a lower pressure than the cryataline isotherm, for a given. volume. This means that it may be possible, at some pressure, the "Iiquid" phase of

$L i$ is more stable than the crystalline $(*)$.

We conclude that the magnitudes of the static energies of the amorphous and crystalline phases of the alkali metals could be very close. Then the configuration of the stable state at $T=O K$, therefore, is determined by the values of the respective zero point energies. In light of the present results, it is worth taking another look at the maximum in the melting curve of cesium [11]. Particular$1 \mathrm{y}$, if our assumption about the equality of the energies of the amorphous and crystalline phases are correct, it may be possible to explain the change from the positive to the negative slope of the melting curve for cesium without invoking arguments about the $s-\alpha$ electronic transition.

\section{References}

[1]Makarenko I.N., Nikolaenko A.M., Ivanov V.A., Stishov S.M., 'Zh.Eksp.Teor. Fiz. 69 (1975) 1723.

[2] Makarenko I.N., Nikolaenko A.M., StIshov S.M., "Liquid Metals" eda. R.Evans and D.A.Greenwood, Institute of Physica Conference Series number 30 (1977) [3]Vaks V.G., Kravchuk S.P., Trefilov A.V. F1z.Tverd.Tela 19 (1977) 1271.

[4] Swenson C.A., J.Phys.Chem.Solids 27

(*) The difference between th pressures for "Iiquid" and cryatalline lithium may be a result of the failure of our ass mption that the systems are classical $\left(1 . e ., T \gg t_{D}\right)$. 
(1966) 33.

[5]Beecroft R.I., Swenson C.A., J.Phys. Chem.Solids 18 (1961) 329.

[6]Monfort C.E., Swenann C.A., J.Phys. Chem.Solids 26 (1965) 291.

[7] Swenson C.A., Phys.Rev. 99 (1955) 423. [8]Anderson M.S., Gutman F.J., Packard J.R Swenson C.A., J.Phys.Chem. Solids 30 (1969) 1587.

[9]Crawford R.K., Daniela W.B., J.Chem. Phys. 50 (1969) 3171.
[10] Stishov S.M., Fedosimov V.I., Makarenko I.N., "Uravnenie sostoyania 1 kristallizatsiya argona" (Equation of State and Crystallization of Argon). Preprint of the Institute of Cryatallography of the USSR Academy of Sciences, hoscow (1972).

[11] Stishov S.M., Uso.Fiz.Nauk 114 (1974) 3.

[12] Martin D.I., Phys.Rev. 139 (1965) 150. [13]Barett C.S., Acta Cryst. 2 (1956) 671 . 